\title{
Digital ecosystem of the region and the competitiveness of Kuzbass coal enterprises
}

\author{
Lyudmila Samorodova ${ }^{1}$, Larisa Shut'ko ${ }^{1}$, Yulia Yakunina $^{1}$, Oleg Lyubimov $^{1}$, and Péter \\ Kovacs $^{2}$ \\ ${ }^{1}$ T.F. Gorbachev Kuzbass State Technical University, 650000 Kemerovo, 28 Vesennyaya St., the \\ Russian Federation \\ ${ }^{2}$ University of Miskolc, H-3515 Egyetemváros, Miskolc, Hungary
}

\begin{abstract}
The issues related to the formation of the digital ecosystem in the coal-mining region within the framework of the world project "industry 4.0" are investigated. It is proved that the prospects for the development of the coal-mining region are associated with its export orientation and diversification of the economy, its complication. Technological momentum based on the use of digitization and cyber-physical systems will lead to a significant reduction in the cost of time for the implementation of manufacturing operations, which enhances the market potential of manufactured production, its competitiveness by reducing production costs, the energy costs of its manufacture and, accordingly, offered prices. The most active processes are the formation of the digital ecosystem and the use of the "Internet of Things" in the mining industry, which indicates a new stage of restructuring in this industry. Russia has accumulated "positive" experience related to the implementation of projects "smart mine" and "intellectual open-cast mine" in Kuzbass mines and coal cuts. The increasing complexity of the regional ecosystem through digitalization and automation of production will contribute to the growth of competitive advantages and competitiveness of Kuzbass coal-mining enterprises.
\end{abstract}

\section{Introduction}

Competitive struggle for leadership between countries, regions and companies is taking place in the modern world in the field of digital economy on the basis of new forms of organization of production, providing a significant increase in productivity in the industrial sector of the economy and the spread of synergetic effect to other industries and fields of activity.

The strategy of industrial development of Russia within the framework of the program "Digital economy of the Russian Federation" developed in 2017-analogue of the German program "Industry 4.0" (2011) - was a response to changes in the ecosystem [1] in the fourth industrial revolution [2]. According to the experts, the industrial revolution of 20202035 and the implementation of the road maps "TechNet" and "Development of technologies in the field of the Internet of Things" of the program "Digital economy of the Russian Federation" by 2024 will lead to an increase in labor productivity in Russia by $30 \%$. By 2035, the increase in labor productivity should be $95 \%$, new sectors will produce 
about $10 \%$ of GNP. "TechNet" is the direction of the program of transition to the fourth technological order in Russia, in the industrial direction of the development of the "Internet of Things" connected with digital design and modeling, 3D printing and robotization of production facilities [2]. According to the Ministry of Industry and Trade, mainly the Russian industrial revolution will work on the domestic market. The share of machinery and equipment in Russia's exports will not grow too much - from $8 \%$ to $13 \%$ by 2024 . The share of Russian engineering companies in the world market will increase to $1.5 \%$ by 2035 , which may well be ensured by the preservation of the current positions on the world market by "Rosatom" structures. Over the next three to four years, the EU will invest about 140 billion euros in Industry 4.0, and labor productivity should increase by $18 \%$ [3].

Prospects for the development of the coal-mining region are traditionally associated with its export orientation and diversification of the economy [4-5]. In the context of the fourth industrial revolution, countries and regions with a high economic complexity index (ECI) or economic complexity index will compete in the markets. In accordance with the method of calculation of this indicator, the detection of the level of complexity of the economy of the country (region) is based on "two main criteria:

1. Economic diversity is a criterion reflecting the number of different goods a country (region) is capable of producing.

2. Economic universality is a criterion that shows the number of countries (regions) that can also produce these goods" [6-7].

Thus, competitive advantages of the territory (the company), is able to produce (and export) complex industrial goods that can not be repeated by others in the economy or the market participants. Moreover, diversification of products and technological progress in one sector generates synergetic development of other related industries [8].

\section{Materials and Methods}

It should be noted that the well-being of the population in countries with a high index of economic complexity is higher than in other countries with lower values of this indicator. According to the rating compiled in 2015, the level of complexity of the country's economy was as follows: The 1st place - Japan, the 2nd place-Switzerland, the 3rd place - Germany and the 4th place - South Korea, the 9th place - the USA, the 19th place - China (2014), the 33rd place - Canada, the 50th place - Russia (2014).

Russia is the 16th largest export economy in the world. In 2016, exports to Russia amounted to 282 billion dollars. Imports total \$ 180 billion and imports \$180 USD billion. This resulted in a trade surplus of us $\$ 102$ billion US dollars, resulting in a trade surplus of us \$ 1.25 USD billion. In 2016, Russia's GNP was \$ 1.28 trillion US dollars. The United States, and its GNP per capita amounted to 23.2 thousand dollars. USA. In the ranking by the level of economic complexity in 2016, Russia took the 34th place [9-11]. The impetus for the complication of the Russian economy was the active development of import substitution, due to international sanctions.

The results of the research of Russian regions conducted by Russian economists correspond to the standard conclusions:

1. The greatest potential for export complication is found in regions with a high level of complexity of economies.

2. The growth of the economies of the regions is largely associated with the diversification and complication of exports, including commodity regions are less likely to export development.

This is due to the fact that "in these regions, there are only a small number of production factors, such as human capital, infrastructure, equipment or certification, with the help of which new export goods can be produced. Creating much of the spectrum of factors needed 
for diversification is expensive and risky. Great opportunity for diversification exists in those regions where a significant part of the ingredients for the production of new export commodities already exists. The regions with certain economies are mainly located in the Western part of Russia. The industrial diversification of the Eastern and other less industrialized regions is therefore more costly. To complicate their export baskets, significant investments are needed, not only of a productive nature. Large expenditures are available to the budgetary constraints of industrialized countries" [12]. Table 1 shows the values and place of a number of Russian regions by the level of the index of economic complexity.

Table 1. Ranking of regions in 2013 [13].

\begin{tabular}{|l|c|c|}
\hline \multirow{2}{*}{ Region } & \multicolumn{2}{c|}{ The index of economic complexity } \\
\cline { 2 - 3 } & Value & Rating \\
\hline Kemerovo Region & 0,104 & 52 \\
\hline Krasnoyarsk Region & 0,057 & 56 \\
\hline Moscow Region & 1,362 & 1 \\
\hline Novosibirsk Region & 0,306 & 27 \\
\hline Tomsk Region & $-0,005$ & 60 \\
\hline $\begin{array}{l}\text { Khanty-Mansiysk Autonomous Okrug - } \\
\text { Yugra }\end{array}$ & $-0,020$ & 62 \\
\hline
\end{tabular}

The development of the coal-mining region in the future is associated with an increase in the potential of its economic complexity, digitalization of the industry and access to new principles of business process management and data exchange at the enterprise level (Fig.1). The implementation of the program "Development of technologies in the field of the Internet of Things" allows to implement for the cross-cutting integration of business processes through the use of different sources of information from different enterprises and optimization of management of different resources through the entire value chain in automatic mode. Ultimately, an ecosystem of enterprise-level and region is formed, covering enterprise partners, and the benefits from cooperation through the development of control system for production, more than competition with each other. In accordance with the concept of ecosystem by J. Moore "for the implementation of any innovation partnerscustomers and provider partners are needed. And the more radical (and often more valuable) the innovation, the more, deeper and wider other players, especially consumers, should be involved. In modern conditions cooperation, cooperation with suppliers and consumers, exchange of experience with producers occupying close market niches become much more important factor of success, than irreconcilable competition" [15]. The system of interaction between the participants of the digital ecosystem allows them to use the common infrastructure and interface of the platform, to create new products that could never create one by one, as well as to create their own products, and to move the common solution. 


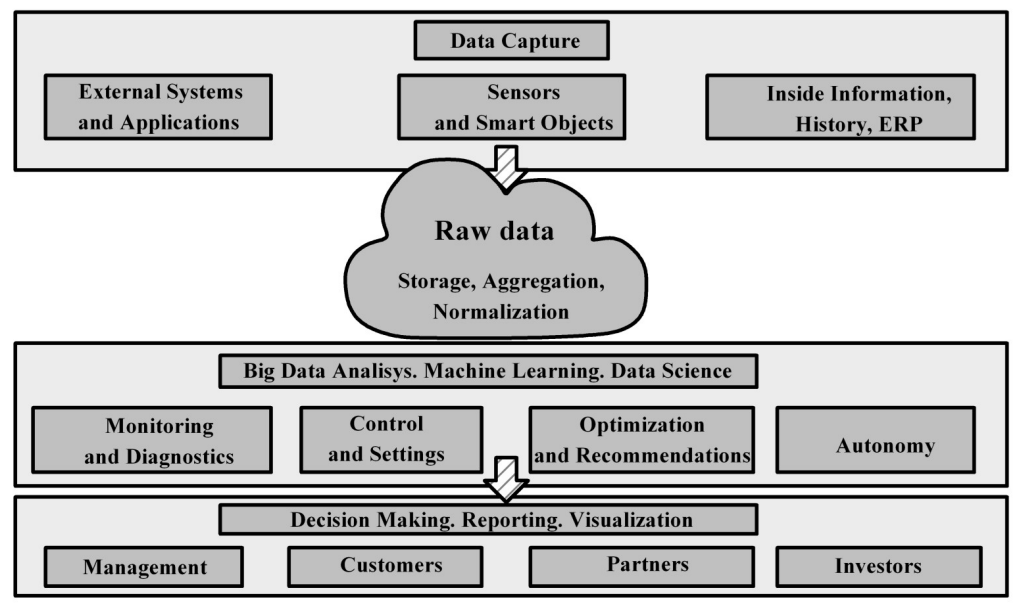

Fig.1. The scheme of control and data exchange.

The Central element of the Internet of Things ecosystem and complex projects with a high degree of automation, a large number of participants and connected devices are the Internet of Things (IoT) platform, which acts as an intermediary as a set of devices transmitting data in a wide range of formats using various communication protocols. The platform provides their collaboration, makes it possible to develop user applications and services. As a rule, developers support the most complete list of preinstalled sensors and devices, standards, protocols, analytical tools to ensure the rapid integration of solutions. According to optimistic forecasts of Gartner, the overall economic effect of the introduction of the Internet of Things in all sectors of the economy on a global scale will be 1.9 USD trillion by 2020 .

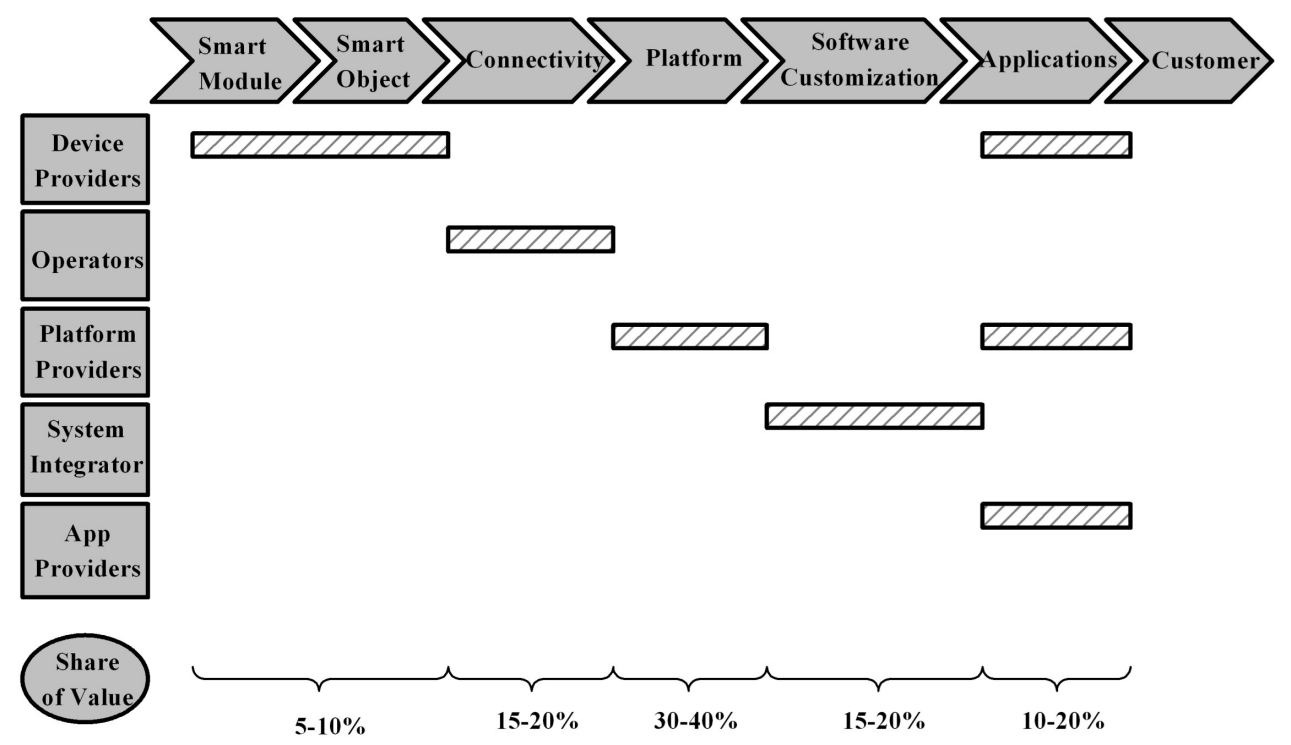

Fig. 2. The added value chain of the IoT project. 
In a digital environment, the organization of work varies across the value chain (Fig.2). Integration of software, work in the cloud storage, data analysis have to be combined with the design, production and technical support of complex "physical" equipment. The classic control model breaks down with the advent of smart devices. There is a steady user interaction, monitoring equipment, recommendations, predictive maintenance, optimization, replacing, adding new features, and so on. New functional links appear in the structure of enterprise management:

- data management division;

- continuous product development unit-DevOps is responsible for the operation of "smart" devices and their optimization once the devices are already in use. It already employs programmers-developers (dev), IT specialists, production and service personnel (ops).

- new development methodologies are being implemented in organizations within separate development departments (Development/Software Engineering), IT operations department (Technology Operations), quality assurance department (Quality Assurance).

- customer experience management department, which oversees the use of equipment, creates recommendations for improvement, provides constant interaction with the client.

\section{Results and Discussion}

In a digital ecosystem of the organization IT division and R \& D are closely cooperate for the speedy implementation of improvements and updates. The effect that the company receives as a result of organizational changes depends on the art of processing the obtained data. Thus, information becomes an asset that affects business performance. In addition, the more partners in a single network and the economy, the smarter it is, because machine algorithms allow to identify patterns, provide models and generate recommendations. Ultimately, the use of digital and cyber-physical systems will lead to increased productivity through a substantial reduction in production time, reduction of production costs and consumption of electricity for the manufacture of products, which increases its market potential and the possibility of reducing supply prices. Qualitative analysis of data according to the estimates of foreign experts allows to increase productivity from 3 to 15 $\%$. The two main directions of the program "Digital economy of the Russian Federation", "Internet of Things", and "automation and robotization of production processes" - cover all processes of mining production [16].

In modern conditions, there is a transformation of coal mining companies into digital companies, in which many standard business processes are already automated, the hierarchy and relationships within companies are changing, the order of interaction with the entire industry ecosystem with competitors, suppliers and customers. Automation of operations continues in the area of operations management, and the information system makes the process cheaper, more reliable and more efficient. The interrelationship between industrial wireless infrastructure (IoX), traditional industrial enterprises and "Industry 4.0" within the digital ecosystem of the region is shown in figure .3 . 


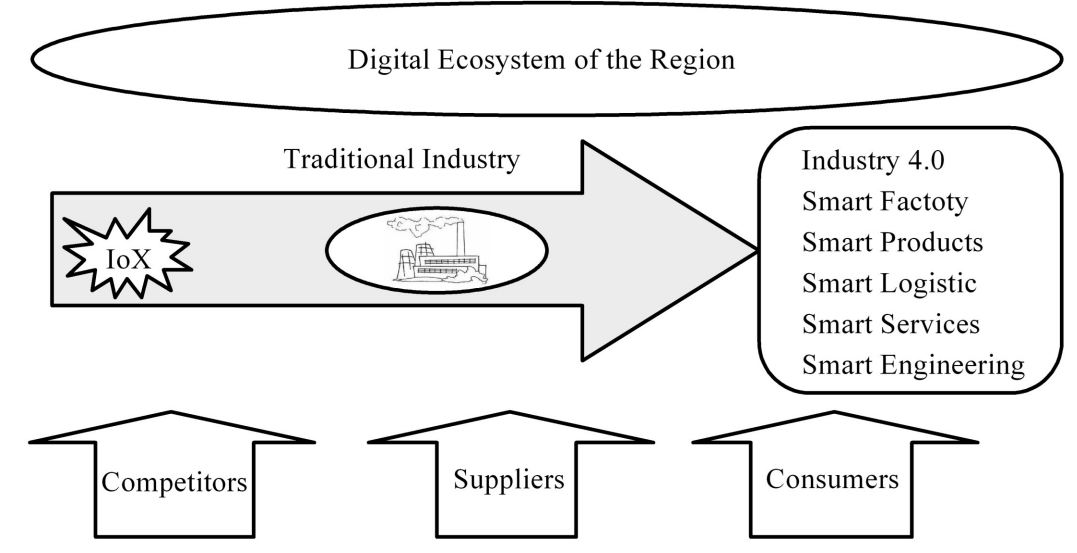

Fig. 3. Digital ecosystem of the region's economy.

Siberian coal energy company (SUEK) is already at the stage of digital transformation, and its main product is "digital coal". Coal as a" digital product" means that due to various information systems and automated systems (trade and logistics systems), closely integrated with each other, production systems and the ERP core, it is possible to control the movement and quality of each shipment of coal at minimum operating costs to the end user. The formation of a flexible production chain is of particular importance for coal sales, especially in the spot market, which brings the company's main margin [17].

Currently, there is already a positive experience of application in the mines of SUEK complex "Smart mine", developed by NPF "Granch" as a single information-butmanagement infrastructure designed to monitor and control any process equipment in the mine, provide communication and alarm, surveillance, warning and search for people caught by the accident. In addition, it includes a multi-functional measuring system lamp control. The system makes it possible to locate miners in the mine with an accuracy of up to $20 \mathrm{~m}$, as well as to monitor methane concentration. "Smart mine" implements the so-called "triangle of miner's safety". A miner is always in touch; ground services always know its location; the atmosphere around it is always under the control of the controller. The decrease of the complex "Smart mine" in comparison with alternative systems (in the Russian market the nearest competitor firms from Australia) is that the system operates on the basis of the principle of determining the location of the object and its trajectory of movement throughout the entire length of the mine at any point; maintains continuous communication with each underground worker; all messages to workers are transmitted by a human voice, the system of "communication" with the workers is built into the individual lamp on the miner's helmet. In addition, there is also a sensor for gas analysis of the atmosphere.

In this respect, the miner also acts as a means of moving the sensor along the mine. According to the technical level, this warning device with the functions of a head rechargeable lamp is a modern communicator, in many respects exceeding the well known brands, with the functions of a measuring device. Due to the stationary fixed sensor, which is equipped with a mine and moving (on the miners' helmets) in the entire shaft is continuous large-scale scanning gas analysis, the mine is under constant control. Moreover, information about methane or other problems in the mine is automatically sent to all mine managers and sent to the head office, which guarantees that appropriate measures are taken if necessary. In general, this Russian technology is at least $40 \%$ cheaper than imported analogues. 
The mines "Uzhnaya" (holding company "Sibiskiy Delovoy Souz" SDS) and "Kotinskaya" ( "SUEK-Kuzbass"), "Russkiy Ugol", "Raspadskaya" have already acquired the status of "smart" mines. Also, 20 coal mines of Kuzbass were supplied with various modifications of the "Smart mine" system [18]. In the near future, it is planned to use at coal mining enterprises equipment with sensors, drones, which will have to transmit an image, produce a $3 \mathrm{D}$-scan of mine workings, measure the temperature, as well as the gas situation.

"VIST Group" (SKOLKOVO Foundation) has been working on the project "Intellectual open-cast mine" for several years [18]. The structure of the system "Intellectual open-cast mine" consists of 4 blocks:

- I block-- autonomous dump trucks, remotely controlled equipment (excavators, loaders, bulldozers, drilling rigs), autonomous railway transport;

- II unit - control center, including: software control of autonomous technology; automatic dispatching and optimization; work places remote control;

- III unit-- wireless data transmission system;

- IV block--high-precision satellite and inertial navigation systems.

The stages of implementation of the project "Intellectual open-cast mine" are as follows:

- the robotic transportation of rock mass by dump trucks on a fixed route between stationary points of unloading and loading;

the robotic transportation by truck of the rock mass between the excavators and unloading point without equipment remote control of excavators and other equipment;

- the robotic transportation by dump trucks of rock mass using remote-controlled equipment (excavators, bulldozers, loaders, etc.).

Today, the automated control system mining complex named "Kar'er", which is the basis for the construction of robotic mining production, is implemented in large mining enterprises of "SUEK", "Holding company "SDS-Ugol", "Mechel-Mining", "Managing company "Kuzbassrazrezugol", "Managing company "Colmar", and others. In general, the creation and commissioning of the system "Intellectual open-cast mine" will allow to reduce the production costs of open-pit mining; ensure safe coal mining in hard-to-reach and difficult climatic regions; "soften" the problem of shortage of qualified personnel.

The technology "Intellectual open-cast mine" is being implemented today in the open-cast mine "Pervomayskiy" (on the site of Sokolovskoye field of the Kemerovo region) by "Holding company "SDS “. This section uses an electronic blasting system. The exposed rock is sent to the filling waste spaces, and the use of heavy equipment allows to reduce the impact on the environment. The dispatching system is based on the use of the GLONASS system. Land reclamation is applied during the whole time of the enterprise work, there is no noise or dust, as in other sections. In the short term, "SUEK" intends to form an "experimental fleet of unmanned dump trucks".

\section{Conclusion}

The fourth industrial revolution, which is based on the use of the "Internet of Things" in industry, digitalization of production characterizes the new stage in the development of coal-mining regions, increasing the complexity of their economies and the competitiveness of enterprises in the field of coal mining and enrichment. The article shows that the Kuzbass coal region is actively involved in the processes of formation of the digital ecosystem and the implementation of road maps "TechNet" and "Development of technologies in the field of the Internet of Things" in the framework of the Russian project "Digital economy of the Russian Federation". The transformation of the mining companies in the digital company, the introduction of technologies of "Smart mine", "Intellectual 
open-cast mine" allows you to create a new product such as "digital coal", to optimize the business processes and the structure of enterprises, reduce production costs and increase productivity, to build relationships with competitive rents, suppliers and consumers within the emerging regional digital ecosystems.

\section{References}

1. J. Moore, The Death of Competition (Collman, New York, 1996)

2. K. Schwab, The Fourth Industrial Revolution (Logan, New York, 2016)

3. Approval of the program "Digital economy of the Russian Federation" by the Government of the Russian Federation from July 28, 2017 No. 1632-R// 31.07.2017. URL: http://government.ru/

4. S. Zhironkin, S. Demchenko, G. Kayachev, E. Taran, O. Zhironkina, E3S Web of Conf., 105, 03008 (2019)

5. C. Bülow, Das Kusnezk-Becken in Sibirien: Entwicklungsstrategien zur Modernisierung einer altindustriell geprägten peripheren Region (Springer, Berlin, 2017)

6. H. Klüter, Geograph. Rundsch., 49, 723 (1997)

7. C.A. Hidalgo, R. Hausmann, PNAS, 30, 123-131 (2009)

8. S.A. Zhironkin, K.A. Kolotov, A.E. Genin, F.V. Agafonov, S.A. Kovalevsky, IOP Conf. Ser.: Earth Environ. Sci., 50:1, 012011 (2017)

9. V. Trifonov, O. Loyko, D. Nesteruk, S. Zhironkin, E. Strekovtsova, AIP Conference Proceedings, 1800, 050009 (2017)

10. Economic Complexitiy Rankings (ECI). URL: https://atlas.media.mit.edu/en/rankings/countryeci/

11. M. Cehlár, K. Teplická, A. Seňová, 11th International Multidisciplinary Scientific Geoconference and EXPO - Modern Management of Mine Producing, Geology and Environmental Protection, SGEM 2011, 1, 913-920 (2011)

12. R. Hausrnmann C., Hidalgo, S. Bustos, M. Coscia, The Atlas of Economic Complexity: Mapping Pathsto Prosperity (MIT Press, Boston, 2011)

13. I.L. Lyubimov, M.A. Gvozdev, M.V. Kazakova, V.K. Nesterov, Journal of New Economic Association, 2:34, 94-122 (2017)

14. The rating of the Russian Regions. URL: https://iep.ru/files/text/nauchnie_jurnali/kazakova_NEA_2-2017.pdf

15. M. Prokudina, O. Zhironkina, O. Kalinina, M. Gasanov, F. Agafonov, E3S Web Conf., 21, 04003 (2017)

16. L. Samorodova, L. Shut'ko, Yu. Yakunina, O. Lyubimov, E3S Web Of Conferences, 41, 04011 (2017)

17. S. Zhironkin, O. Aleshina, V. Gorev, Y. Gunyakov, O. Zhironkina, E3S Web of Conferences, 105, 04001 (2019)

18. Ju. Platkin, L. Platkina, Mining industry, 1:137, 22-28 (2018) 